\title{
Review
}

\section{An overview of Staphylococcus epidermidis and Staphylococcus aureus with a focus on developing countries}

\author{
Daniela Chessa*, Giulia Ganau*, Vittorio Mazzarello \\ Department of Biomedical Science, School of Medicine, University of Sassari, Sassari, Italy \\ * Both authors equally contributed to this work.
}

\begin{abstract}
Most nosocomial infections by Staphylococcus epidermidis and Staphylococcus aureus have gained considerable attention due to an increase of infections caused by these strains that have been reported in recent years throughout the world.

Most notably, it is important to underline the presence of $S$. epidermidis and $S$. aureus in the human epithelia microflora and to highlight that it is impossible to eradicate them from humans.

There are various virulence factors that normally sustain the infection life cycle, such as antibiotic resistance (methicillin resistance). Furthermore, it is important to evaluate the usefulness of typing the spa gene from isolated strains in order to study genotypes and geographical distributions. In the present review, different cases related to patients infected by Staphylococci and an overview of this problem worldwide are reported.
\end{abstract}

Key words: Staphylococcus spp.; nosocomial infections; developing countries.

J Infect Dev Ctries 2015; 9(6):547-550. doi:10.3855/jidc.6923

(Received 26 March 2015 - Accepted 26 April 2015)

Copyright $(92015$ Chessa et al. This is an open-access article distributed under the Creative Commons Attribution License, which permits unrestricted use, distribution, and reproduction in any medium, provided the original work is properly cited.

\section{Introduction}

The human body is the habitat of large and varied populations of bacteria with proprieties that are at the same time potentially dangerous and helpful to human health; for this reason, in recent years, there has been a strong impulse to fully characterize the strains associated with different parts of the body under different health conditions [1]. Thus, this innocuous commensal microorganism is now globally seen as an important opportunistic pathogen related to different infections. Staphylococcus aureus together with Staphylococcus epidermidis rank first among causative agents for these kinds of commensal infections. Therefore, they became the major causes of infections of medical implants and nosocomial infections worldwide, and especially in developing countries [2].

\section{Staphylococcus aureus spread}

Staphylococcus aureus is a Gram-positive bacterium, and it is a major pathogen in humans and animals, causing a wide variety of illnesses ranging from skin and soft tissue infections to life-threatening invasive diseases. The pathogenesis of a particular $S$. aureus strain is attributed to the combined effect of extracellular factors and toxins, together with the invasive properties of the strain such as adherence, biofilm formation, and resistance to phagocytosis.

S. aureus has long been recognized as a virulent pathogen able to cause bacteremia strongly associated with higher mortality compared to other bacterial blood stream infections [3]. The habitats of Staphylococcus are the nasal membranes and skin of warm-blooded animals, and they may cause a wide range of infections, such as skin infections, food poisoning, pneumonia, sepsis, osteomyelitis, and infectious endocarditis [4].

$S$. aureus is also an important agent of food poisoning because it can be found in water, dust, and air. In Nigeria and many other parts of the developing world, chickens live close to human dwellings and therefore play an important role in environmental contaminations; in addition, birds are vehicles for transmission of those pathogens to humans through the handling live birds or consumption of contaminated meat and other poultry products [5].

A study in Thailand showed a nasal colonization from these strains and the ease of infection transmission between hospital worker students [6]. In 
recent years, methicillin-resistant $S$. aureus (MRSA) has become an increasing problem in Southeast Asia, despite improvements in healthcare and increased hospitalization rates. In China, for instance, between 2003 and 2013, S. aureus infections in hospitals were reported to be caused by MRSA strains in more than $60 \%$ of cases [7]. The MRSA strains are a problem worldwide, mainly in developing countries, which have special difficulties since alternative therapeutic options are either unviable or unaffordable. Moreover, in developing countries, antibiotic use is even less controlled, and many antibiotics are available without a doctor's prescription (64\%) [4]. In Zimbabwe, there are studies that tried to use plant compounds instead of common drugs because they are more affordable to the population and because this new therapy could avoid the problem of multiple-resistant drugs [8].

\section{Staphylococcus epidermidis spread}

Staphylococcus epidermidis is isolated prevalently from human epithelia and colonizes predominantly the axillae, head, and nares [9]. S. epidermidis belongs to the group of coagulase-negative staphylococci (CoNS), which is discriminated from coagulasepositive staphylococci such as $S$. aureus by its lack of the enzyme coagulase [10].

Indeed, this pathogen is part of the human epithelia microflora and for this reason has a benign relationship with the host, but $S$. epidermidis has emerged as a pathogen causing different infections. Particularly, S. epidermidis represents the most frequent causative agent involved with infections involving any kind of medical devices, such as peripheral or central intravenous catheters [11]. Specifically, catheter-related infections are associated with increased mortality and contribute to an increased length of hospital stay and higher healthcare costs, which are problematic in limited-resource settings such as South Africa [12,13]. In three different hospitals Iran, nasal swabs were collected from 163 healthcare workers; 96 were cultured and resulted positive for S. epidermidis [14]. Similar results were reported in a study performed between 2000 and 2009 in a hospital in Kenya, where in blood samples collected from neonates, S. epidermidis accounted for $33 \%$ of the isolated strains [15]. Furthermore, a study carried out in Brazil showed that $2.7 \%$ of $S$. epidermidis strains were isolated from hospital healthcare wastes, indicating a potential risk of spread outside the hospital setting [16].

\section{Spa typing}

$S$. aureus encodes various virulence factors including the surface Ig-binding protein A (spa), whose function is to capture $\operatorname{IgG}$ molecules in the inverted orientation and therefore avoid phagocytosis of bacterial cells by the host immune system [13,12].

Typing the highly variable $\mathrm{X}$ region of the spa gene is one of the most common methods for $S$. aureus genotyping. Spa typing also facilitates communication and data comparison between national and international clinical laboratories; therefore, this gene contributes to understanding the diversity, carriage, and transmission of $S$. aureus strains in different populations [17]. Various studies reported different data; in a study carried out in Ghana, this strain was detected in patients affected by Buruli ulcer lesions who tested positive for $S$. aureus of 13 spa-types. A total of $26 \%$ of the study participants carried the same $S$. aureus genotype in their anterior nares and wounds; $16 \%$ were colonized with isolates belonging to two different genotypes at the same time, and $26 \%$ of patients were colonized with different $S$. aureus types over time [18].

\section{Antibiotic resistance}

It has been reported by the World Health Organization (WHO) that in some African regions, $80 \%$ of Staphylococcus aureus infections are methicillin resistant, meaning that treatment based on standard antibiotics is not effective. Methicillin resistance is an independent risk factor for mortality in S. aureus bacteremia [19]. A number of South African studies have characterized the contribution of $S$. aureus to bacteremia in children; for instance, a study performed on hospitalized children in Cape Town, where the proportion of MRSA has been increasing over the last few years, showed that $11.6 \%$ of bacteremia was due to S. aureus [20]. Infectious diseases are still the leading causes of death in children in developing countries, with neonates bearing the highest burden. In Africa alone, infectious diseases account for over $76 \%$ of deaths among children, and an estimated $36 \%$ of neonatal deaths worldwide are directly attributable to severe infections [21]. In these studies, $S$. aureus MRSA was reported to be the pathogen responsible for $3 \%$ to $63 \%$ of deaths [22].

\section{Conclusions}

This review aimed to underline the important problem of infections due to pathogens that are normally part of the human microflora, which is 
emerging in all countries with a higher prevalence in developing countries.

Eradication of staphylococci might be difficult because the absence of these bacteria would be counterproductive, as they may be replaced by more harmful microorganisms; it is necessary to find a balance with these bacteria.

Specific antibiotic-resistant genes are widespread in staphylococcal infections, and this is a problem since methicillin is an antibiotic of first choice against these types of infections. Among hospital isolates of $S$. epidermidis, methicillin-resistant strains represent between $75 \%$ and $90 \%$ of cases, which is even higher than the rate reported for S. aureus (40\%-60\%).

Furthermore, the best way to deal with $S$. epidermidis and $S$. aureus infections is based on prevention, which includes appropriate sterilization of medical equipment, patients' body areas, and healthcare personnel potentially in contact with indwelling medical devices during surgery and life routines during hospital admission [23].

\section{Addendum}

We dedicate this work to Prof. Cappuccinelli, a major contributor to this and other infectious disease research projects in the field of human microbiology and neglected tropical diseases. Throughout the years, he has transmitted to our team both the method and passion for scientific research.

\section{References}

1. Urbaniak C Cummins J, Brackstone M, Macklaim JM, Gloor GB, Baban CK, Scott L, O'Hanlon DM, Burton JP, Francis KP, Tangney M, Reid G (2014) Bacteria microbiota of human breast tissue. Appl Environ Microbiol 80: 3007-3014. doi: 10.1128/AEM.00242-14.

2. Rubino C, Brongo S, Pagliara D, Cuomo R, Abbinante G, Campitiello N, Santanelli F, Chessa D (2014) Infections in breast implants: a review with a focus on developing countries J Infect Dev Ctries 12: 1089-1095. doi: 10.3855/jidc.3898.

3. Thwaites GE, Edgeworth JD, Gkrania-Klotsas E, Kirby A, Tilley R, Török ME, Walker S, Wertheim HF, Wilson P, Llewelyn MJ (2011) Clinical management of Staphylococcus aureus bacteraemia. Lancet Infect Dis 11: 208-222.

4. Kakai R, Wamola IA (2002) Minimising antibiotic resistance to Staphylococcus aureus in developing countries East Afr Med J 79: 574-579.

5. Suleiman A, Zaria LT, Grema HA, Ahmadu P (2013) Antimicrobial resistant coagulase positive Staphylococcus Aureus from chickens in Maiduguri, Nigeria. Sokoto J Vet Sci 11:51-55. doi: 10.4314/sokjvs.v11i1.8.

6. Treesirichod A, Hantagool S, Prommalikit O (2014) Nasal carriage and antimicrobial susceptibility of Staphylococcus aureus among medical students at the HRH Princess Maha Chakri Sirindhorn Medical Center, Thailand: A follow-up study. J Infect Public Health 3: 205-209.

7. Uhlemann AC, Otto M, Lowy DF, Deleo FR (2014) Evolution of community and healthcare-associated methicillin-resistant Staphylococcus aureus. Infect Genet Evol 21: 563-574.

8. Joshua M and Takudzwa M (2013) Antibacterial properties of mangifera indica on Staphylococcus Aureus. Afr J Clin Exper Microbiol 14: 62-74. doi: 10.4314/ajcem.v14i2.4.

9. Kloos WE, Musselwhite MS (1975) Distribution and persistence of Staphylococcus and Micrococcus species and other aerobic bacteria on human skin. Appl Microbiol 30: 381-385.

10. Otto M (2009) Staphylococcus epidermidis - the "accidental" pathogen Nat Rev Microbiol 7: 555-567. doi: 10.1038/nrmicro2182.

11. Rogers KL, Fey PD, Rupp ME (2009) Coagulase-negative staphylococcal infections. Infect Dis Clin North Am 23: 7398.

12. De Beer J, Brysiewicz P, Bhengu BR (2011) Intensive care nursing in South Africa. S Afr J Crit Care 27: 6-10.

13. Rosenthal VD, Bijie H, Maki DG, Mehta Y, Apisarnthanarak A, Medeiros EA, Leblebicioglu H, Fisher D, Álvarez-Moreno C, Khader IA, Del Rocío González Martínez M, Cuellar LE, Navoa-Ng JA, Abouqal R, Guanche Garcell H, Mitrev Z, Pirez García MC, Hamdi A, Dueñas L, Cancel E, Gurskis V, Rasslan O, Ahmed A, Kanj SS, Ugalde OC, Mapp T, Raka L, Yuet Meng C, Thu le TA, Ghazal S, Gikas A, Narváez LP, Mejía N, Hadjieva N, Gamar Elanbya MO, Guzmán Siritt ME, Jayatilleke K (2012) International Nosocomial Infection Control Consortium (INICC) report, data summary of 36 countries, for 2004-2009. Am J Infect Control 40: 396-407.

14. Pourmand MR, Abdossamadi Z, Salari MH, Hosseini M (2011) Slime layer formation and the prevalence of mecA and aap genes in Staphylococcus epidermidis isolates. J Infect Dev Ctries 5: 34-40. 
15. Kohli-Kochhar R, Omuse G, Revathi G (2011) A ten-year review of neonatal bloodstream infections in a tertiary private hospital in Kenya. J Infect Dev Ctries 5: 799-803.

16. Nascimento TC, da Silva VL, Ferreira-Machado AB, Diniz CG (2015) Potential spread of multidrug-resistant coagulasenegative staphylococci through healthcare waste. J Infect Dev Ctries 9: 29-34. doi: 10.3855/jidc.4563.

17. Strommenger B, Braulke C, Heuck D, Schmidt C, Pasemann B, Nubel U, Witte W (2008) spa typing of Staphylococcus aureus as a frontline tool in epidemiological typing. J Clin Microbiol 46: 574-581.

18. Amissah NA, Glasner C, Ablordey A, Tetteh CS, Kotey NK, Prah I, van der Werf TS, Rossen JW, van Dijl JM, Stienstra Y (2015) Genetic Diversity of Staphylococcus aureus in Buruli ulcer. PLOS Negl Trop Dis 9: e0003421. doi: 10.1371/journal.pntd.0003421.

19. Kaasch AJ, Barlow G, Edgeworth JD, Fowler VG Jr, Hellmich M, Hopkins S, Kern WV, Llewelyn MJ, Rieg S, Rodriguez-Baño J, Scarborough M, Seifert H, Soriano A, Tilley R, Törők ME, Weiß V, Wilson AP, Thwaites GE (2014) Staphylococcus aureus bloodstream infection. J Infect 68: 242-251.

20. Naidoo R, Nuttall J, Whitelaw A, Eley B (2013) Epidemiology of Staphylococcus aureus Bacteraemia at a Tertiary Children's Hospital in Cape Town, South Africa. PLoS ONE 8: e78396. doi:10.1371/journal.pone.0078396.

21. Liu L, Johnson HL, Cousens S, Perin J, Scott S, Lawn JE, Rudan I, Campbell H, Cibulskis R, Li M, Mathers C, Black
RE (2012) Global, regional, and national causes of child mortality: an updated systematic analysis for 2010 with time trends since 2000. Lancet 379: 2151-2161.

22. Huynh BT, Padget M, Garin B, Herindrainy P, KermorvantDuchemin E, Watier L, Guillemot D, Delarocque-Astagneau E (2015) Burden of bacterial resistance among neonatal infections in low income countries: how convincing is the epidemiological evidence? BMC Infect Dis 15: 127. doi: 10.1186/s12879-015-0843-x.

23. Ziebuhr W, Krimmer V, Rachid S, Lössner I, Götz F, Hacker J (1999) A novel mechanism of phase variation of virulence in Staphylococcus epidermidis: evidence for control of the polysaccharide intercellular adhesion synthesis by alternating insertion and excision of insertion sequence element IS256. Mol Microbiol 32: 345-346.

\section{Corresponding author}

Daniela Chessa

Dipartimento di Scienze Biomediche

Università degli Studi di Sassari

Viale San Pietro, 07100

Italy

Phone: +393283725195

Email: danielachessa@uniss.it

Conflict of interests: No conflict of interests is declared. 